\title{
The need for new teaching praxeologies in the paradigm of questioning the world
}

\author{
Jean-Pierre Bourgade, Karine Bernad, Yves Matheron
}

\begin{abstract}
The introduction of inquiry-based instructional formats at secondary and tertiary levels reveals some difficulties related to missing teaching praxeologies. Indeed, the paradigm of visiting works is dominant in those institutions where a "teacher pedagogy" is widespread: managing inquiry-based activities requires a "pedagogy of inquiry" which is based on distinct teaching praxeologies. The aim of this chapter is to present two research studies presenting didactic analyses of the exploration of different teaching types of tasks related to the implementation of study and research paths, paying special attention to the exchanges between teachers and researchers working in the same team.
\end{abstract}

\section{INTRODUCTION}

We study issues related to the dissemination and reception of study and research paths (SRPs, see Glossary) (Chevallard, 2007). The notion of SRP, as an extension of the concept of study and research activity (see Glossary), has emerged within the ATD in order to contribute to the development of teaching formats that make it possible to establish a functional relationship of individuals to knowledge. Indeed, in France, the paradigm of visiting works (Chevallard, 2002) is dominant in those institutions where a "teacher pedagogy" (Marietti 2009, Chevallard 2007) is widespread: the raison d'être of the knowledge to be studied is most likely not encountered by students; the students' topos (see Glossary), or even their role in the study process, is limited. The implementation of SRAs includes the formulation of so-called generating questions, the study of which leads to the encounter of a certain number of mathematical organizations that function as tools for producing answers to the initial question, as well as to other sub-questions arising from that place. Setting such study processes in "ordinary" classes raises a number of issues (Matheron \& Noirfalise, 2011), essentially due to the discrepancy between these processes and classical didactic forms, which are typical of the "pedagogy of teachers" (like lecture-based courses, interactive lectures, teaching through imitation, etc.). Typically, high school students in France are expected neither to elaborate new techniques nor to justify their efficacy: this falls into the teacher's topos.

With regard to the emergence of questions, students rarely take responsibility for studying them independently of the teacher's didactic intentions. Besides, within the framework of the paradigm of questioning the world, a "pedagogy of inquiry" would give a critical role to questions and the topos of students. Indeed, in this case, the aim is to collectively elaborate answers to a question, without prejudging which works might be crossed in the course of its study. As Marietti (2009) puts it:

Today, the transition from the paradigm of visiting works and from a teacher pedagogy to a "questioning" paradigm served by an adequate "pedagogy of inquiry" constitutes an open problem, and an important challenge is not only to train teachers in the pedagogy of 
inquiry, but also to identify praxeological needs for the conception and management of SRPs, and to disseminate praxeologies that fit these needs in the profession of teacher. (p. 85 , our translation)

The difference between paradigms can be made sharper: an SRP is generated by a genuine question $Q$ and, in some sense, it is finalised by the question itself. Therefore, if the answer is (or includes) a given praxeology, this generating question $Q$ provides a strong purpose, a raison d'être, to this praxeology. This, and the difficulty in developing SRPs in some institutions led to the notion of a praxeologically finalised SRP (or, for short, finalised SRP): while the generating question of the process remains prominent, it is generally chosen in order to facilitate or necessitate the encounter with a priori chosen works - mathematical works, for instance. In the paradigm of visiting works, the answer to the question $Q$ is built by the teacher before students even enter in the study of $Q$ (if they ever meet $Q$ ).

In contrast, in the case of the paradigm of questioning the world, the milieu of a genuine inquiry will progressively be enriched by questions $Q_{i}$ derived from the initial question, available answers $\left.A_{j}\right\rangle$ (found on the internet, in books, provided by teachers or students, etc.), a variety of works $W_{k}$ that may be useful for the study of the initial question. In particular, the teacher, indeed rather a study helper, does not impose the study of a given answer $A^{\vartheta}$, or, if she does, this answer as any other must be submitted to the scrutiny of students: produced by a media (the teacher) among others, this answer has to be confronted to various milieus (e.g. calculators, books, other students, etc.) in a media-milieu dialectic. Such SRPs are called praxeologically open SRPs, or, for short, open SRPS.

Furthermore, the model of didactic moments (Chevallard, 2002, see Glossary) can also be used to study any process of construction or dissemination of professional praxeologies related to the implementation of SRPs. In a "pedagogy of teachers", students are seldom given the responsibility to explore the types of tasks and to produce the techniques they have to study, let alone to justify them. On the contrary, in a "pedagogy of inquiry", students are assigned part of the responsibility in the study of a question; they are also given a broader topos in the lead of the study. Specifically, the production of a rich enough milieu facilitates the emergence of a media-milieu dialectics: students have to assess the reliability of every answer raised in the process of study by confronting it to the available milieu. In turn, such answers (accepted or rejected) enrich the milieu, etc. Since they have more autonomy in these dialectic processes, the students are more implicated in the production of techniques (exploratory moment) and of justifications of these techniques (technological-theoretical moment).

In this chapter, we present two didactic analyses of the exploration of different professional types of tasks related to the implementation of finalized and open SRPs, paying special attention to the exchanges between teachers and researchers working in the same team. In the next section, we present the case of a team of researchers and a teacher implementing a finalized SRP at secondary level about the introduction of negative numbers. We study conditions and constraints on the internal didactic transposition's process undertaken by the teacher, starting from the appropriation of a provided document describing an SRP scenario, up to its implementation in the classroom. In the third section, we study the dissemination of a technique for the conception and phrasing of 
generating questions for open SRPs. We observe how university teachers with no previous experience in the "pedagogy of inquiry" take hold of this praxeological equipment. Finally, from the two cases, we extract some conclusions about the dissemination of the pedagogy of inquiry within the teaching profession.

\section{DISSEMINATION OF A FINALISED SRP IN HIGH SCHOOL}

In 2005, a national investigation program, Activités Mathématiques et Parcours d'Étude et de Recherche dans l'Enseignement Secondaire (AMPERES), was initiated by the Commission Inter IREM $^{1}$ Didactique and supported by the French Institute of Education (IFÉ-ENS of Lyon). The aim was to make the mathematics of the program live as by-products of answers to questions, which would provide them with rationales, "raisons d'être". Praxeologically finalized SRPs are considered as a means to facilitate an evolution of ordinary teaching praxeologies. Teaching proposals are elaborated in an iterative process, alternating phases of implementation and phases of didactic analysis. In this inquiry, we focus on issues related to the ecology of finalised SRPs, that is, on the study of the conditions and constraints that facilitate or inhibit the dissemination of SRPs in ordinary classes, in which mathematics from official programmes are taught and no systematic observation of practices is developed. This investigation develops a clinical study (Bernard, 2017) to analyse the didactic techniques activated by a teacher in order to carry out the exploratory and technologico-theoretical didactic moments, that is, the exploration of the type of tasks, the emergence of a technique to realise it, and the production of justifications of this technique.

\subsection{AN OBSERVATION DEVICE}

Since 2012, three teachers in the same high school in Marseilles, involved in the AMPERES project with Yves Matheron et Karine Bernad, were part of the secondary school Associated Educational Place (LeA, in French) Collège Marseilleveyre. Every other week, control meetings were organised in the institution. The three teachers and the two didacticians worked together in the study of the following question: Is it possible to use SRPs to teach all of, or part of the curriculum of a given class? According to Matheron \& Quilio (2015, p. 84), such cooperation must be anchored on what "systemic conditions and constraints allow, on what is expected to be possible for teachers, on what they have built based on their professional experience, and on what they could do with it". Thus, such a LeA generated locally new conditions under specific constraints for the teaching of mathematics: these new conditions hold for the setting up of SRPs for instance.

One teacher, designated as $y$, joined this group in September 2014, to engage in the implementation of an SRP on the teaching of relative numbers in $5^{e}$ (12-13-year-old students). He was provided with a document, denoted: $W_{\text {SRP-LeA }}$. The letter $W$ was chosen concerning the notion of work (Chevallard, 2003) defined in the ATD as "any intentional product of human activity". The fact that the LeA is both a place for experimentation and for the dissemination of this SRP explains the choice of the SRP-LeA index. This document describes the mathematical praxeologies (types of tasks, techniques and justifications) that must be elaborated by the students in the frame of the SRP,

\footnotetext{
${ }^{1}$ Institut de Recherche de 1'Enseignement des Mathématiques.
} 
as well as some information on the techniques the teachers must use to manage the study, and on the justifications of these techniques (technological-theoretical elements). The generating question, on which is based the SRP, is given and the reasons for its choice are explained. It is important to emphasize that $y$ did not contribute to the elaboration of this SRP.

Our analysis is based on the observation of class sessions and control sessions (both videotaped), individual interviews with the teachers (before and after the implementation of the SRP) and two documents that $y$ produced to build an answer to the (possible) questions raised by the implementation of the SRP. In this investigation, the information available in $W_{\text {SRP-LeA }}$ is contrasted to these resources with the following question in mind:

What does $W_{\text {SRP-LeA }}$ provide the teacher with to help him implement the mathematics to be taught? What is made explicit? What adaptations of $W_{\text {SRP-LeA }}$ does he operate to produce his own organisation of the study?

\subsection{OUTLINE OF AN SRP ABOUT RELATIVE NUMBERS}

The SRP under consideration is grounded on the idea that relative numbers can be introduced as shortcuts for calculation programs. This idea is based on the construction of a praxeological model of reference (Gascón, 2014), as a link that ensures an epistemological coherence in the transpositive chain between mathematics and mathematics to teach. One of the "scholarly" mathematical constructions of $Z$ can be briefly described as follows. It is necessary to have previously defined the addition in $Z$ as well as to have established its properties: associativity, commutativity, and regularity of the integers. Then we consider an equivalence relation $R$ in $N \times N$, defined by ( $n$, $m) R\left(n^{\prime}, m^{\prime}\right) \Leftrightarrow n+m^{\prime}=n^{\prime}+m$. Then we proceed to define as the set of equivalence classes for $R$. In our reference model, we define a function from $Z$ to $Z$, called "operator" and noted $O_{(b, c)}$ with $(b, c) \in N \times N$, as follows:

- if $b \geq c$ then $O_{(b, c)}(x)=x+(b-c)$; we say that $O_{(b, c)}$ is an additive operator,

- if $b<c$ then $O_{(b, c)}(x)=x-(c-b)$; we say that $O_{(b, c)}$ is a subtractive operator.

In fact, an operator is a special kind of calculation programme (see Chapter 5) adding to a positive number $x$ the (positive or negative) difference $b-c$

If we call $\Omega$ the set of the operators thus defined and Def. the domain of definition of operator $O$, the relation $R^{\prime}$ defined on $\Omega \times \Omega$ by:

$O_{(a, b)} R^{\prime} O_{(\mathrm{c} d)} \Leftrightarrow \forall x \in \operatorname{Def} . O_{(a, b)} \cap \operatorname{Def} ._{(c, d)}, O_{(a, b)}(x)=O_{(c, d)}(x)$

is an equivalence relation. We thus construct, in the same way, relative integers as equivalence classes for $R^{\prime}$.

For instance, number -1 (that is, $(0,1)$ ) is a shortcut for, say, the following calculation program: $x+61-62$, which can be oralised as: "Take a number, add 61, subtract 62." The organisation of the study, as planned by the designers of the SRP, goes grossly as follows: students are asked to operate some calculations as fast as possible; one possible technique for most of the calculations is to consider them as calculation programs and to find a simpler, equivalent calculation program. For instance, $2650+219-215$ can be seen as a 
realisation of "add 219, then subtract 215"; an equivalent program is "add 4", since "+ 219 $215=+4$ " (“+219" reads "add 219"). At some point, this technique faces a difficulty since, when adding 61 then subtracting 62, one meets the following program, "add 61, then subtract 62 ", which is equivalent to "add - 1": negative numbers are required, which have not been constructed yet. Facing students with this difficulty is one of the goals of the SRP, to lead them to build a new technique - and, thereby, a new type of numbers. In particular, relative numbers are introduced as additive or subtractive operators, obtained as notably simpler representative elements of equivalence classes of calculation programs: this is the rationale, the raison d'être, for relative numbers that is pushed forward in the SRP. The calculations under study are algebraically represented by the formula " $a+b-c$ ", and the students are faced only with situations where $a \geq c-b$ where $a, b$ and $c$ are nonnegative decimal numbers. An equivalent simpler (at least in some situations) calculation program reads: "add $(b-c)$ " (or: "first calculate $b-c$, then add it to the chosen number $a$ ").

\subsection{STUDY OF THE EXPLORATION OF A TYPE OF TASKS AND THE EMERGENCE OF A TECHNIQUE}

The case we are developing in this section is focused on a specific part of the SRP outlined above. According to the document $W_{\text {SRP-LeA }}$, it is expected that the teacher will propose an individual working time to search four calculations such as:

$\left[1^{\text {st }}\right] 2650+219-215 ;\left[2^{\text {nd }}\right] 23+12.3-2.3 ;\left[3^{\text {rd }}\right] 4374+62-61 ;\left[4^{\text {th }}\right] 4374+61-62$.

The indications given in the document are the following:

Students will possibly keep on adding 1 in the $\left[4^{\text {th }}\right]$ calculation, missing the difference with previous calculations. They can be convinced of their mistake by comparing the $\left[3^{\text {rd }}\right]$ and $\left[4^{\text {th }}\right]$ calculations. If we add 62 and then subtract 61 to the same number 4374 , it is likely that we will not get the same result as if we had added one less and subtracted one more. Soon, other students will notice the impossibility to apply the previous technique.

Nevertheless, numbers in these calculations are the same as in the previous calculation, even though their location is different. This, observed by students or, if not, pointed out by the teacher, should lead to a comparison between the $\left[3^{\text {rd }}\right]$ and $\left[4^{\text {th }}\right]$ calculation programmes.

In the observed implementation we are reporting here, the teacher $(y)$ gave the students around three minutes to work out these calculations individually. After that, $y$ took full didactic responsibility for the comparison of the last two calculations.

$y$ : if I consider the last two calculations [4374 + 62 - 61 and 4374 +61 - 62], you said: "you made a mistake, you put the same twice". In fact, I didn't put the same. We realise that [...] if that one is equivalent to adding 1 , intuitively, you feel like saying that that one is equivalent to removing 1 , to subtracting 1 . 
The emerging technique is grounded on mere "intuition" and no analysis is made of the fact that one is led to subtract a greater number from a smaller one. The exploratory moment is soon stopped and mathematical activity is mainly dedicated to the development of technological aspects and to their institutionalisation. It comes out that, instead of letting students analyse the situation and compare the $3^{\text {rd }}$ and $4^{\text {th }}$ calculations, the teacher $y$ not only performed this comparison, but also produced the adapted technique ("if that one is equivalent to adding 1 , intuitively, that one is equivalent to removing 1 , to subtracting 1 "). Next, as a consequence, a student tried to apply the new technique ("subtracting 1") to one of the first (non-problematic) calculations. Indeed, the moment of exploration of the type of tasks and the emergence of the technique was underdeveloped. The teacher indicated the problematic situation:

$y$ : "if you want, to summarise, when the number is greater, when we add more than we subtract, it's easy; it's what we've been doing since last week. That's what you needed!'

The student had not identified the problematic aspect of the task in such situations where $c>b$ : the new technical element appeared to him as a completely new technique that could be applied in any situation, independently of the relationship between $b$ and $c$. Ten minutes later, the teacher proceeded to institutionalise:

y: "That was the problem, and that made our usual strategy fail." Then, he said: "I am only writing the steps of the calculation you just made in your mind. The goal is to write the outcome."

He repeated:

y: "I am just describing the steps. The idea is to do a mental calculation."

The class activity is therefore set at the level of "mental calculation" when, in fact, the true goal of the SRP is to facilitate the emergence of relative numbers as representatives of classes of equivalent calculation programs, which requires to work the notion of equivalent calculation programs out, and to introduce the notation " -1 " as a shortcut for such a calculation program. The teacher prevented this technological elaboration from happening by focusing on the students' attention on mere "mental calculation". This is probably the consequence of the lack of didactic praxeologies necessary to manage the media-milieu dialectic. The observation of any crucial mathematical fact is not facilitated because the teacher provides the full technique and the elements of its justification. Therefore, students do not have the opportunity to compare different strategies, or even to meet several specimens of the same type of tasks. In particular, this analysis reveals some difficulties to develop moments dedicated to the exploration of a problematic type of tasks and to the emergence of a technique to realise it, and also moments devoted to the production of justifications to such a technique, thereby providing new definitions, theorems, etc. (that is, the technological-theoretical moment).

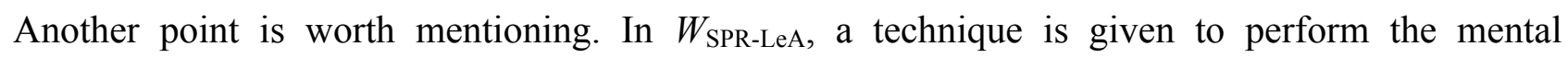
calculation " $a+b-c$ ":

One should oralise the calculation program " $+b-c$ ", calculate the difference $d$ between $b$ and $c$, if $b>c$, or between $c$ and $b$, when $c>b$, then announce respectively: "add $d$ " or "subtract $d$ ". 
Using this technique is of paramount importance for the sake of the development of the SRP: it allows the students to meet calculation programs and their equivalence. In particular, it facilitates the emergence of " -1 " as a notation for the calculation program "subtract 1". However, in the observed sessions, the teacher indicated that this oralisation had no technical function for him. For instance, he said: "if we had to phrase our calculation, what would it be like?" Thus, he seemed to take phrasing as a justification rather than as a technical component. We are faced with what Bosch \& Perrin-Glorian (2013) evoke as effects of logocentrism, a term introduced by the French philosopher Jacques Derrida about the priority given to the oral discourse $(\log o s)$ as a direct reflection of reasoning:

Our culture tends to give speech a semiotic valence that seems to wipe out its instrumental valence, leading us to think of words as signs or signifiers of other objects, instead of also understanding them as technical entities, which are required to implement certain types of tasks - including the types of tasks that consist in pointing to new entities or producing new meanings. (Bosch \& Perrin-Glorian, 2013, p. 288, own translation)

Once again, this should be contrasted with the indications provided in $W_{\text {SRP-LeA }}$ :

Then, it is the task of the teacher to indicate that a specific notation will be used to mean that, applying the result of the subsequent part of the calculation program to the first number, is equivalent to subtracting 1 . The role of students is restricted to the justification of the notation that comes as a simplification of the calculation program.

In the next session, the teacher was supposed to bring a new notation along, such as " $+45-46=-$ 1 ". He said to the students:

$y$ : This is a notation I am showing to you, there is nothing to understand.

One minute later in the same session, $y$ claimed:

$y$ : Here (pointing to the sentence "add 45 and subtract 46 is equivalent to subtracting 1" written on the blackboard), it is written in French, there (pointing to the equality " $+45-46=-1$ "), it is written in maths.

According to $y$, this notation essentially sums the sentence up (it is therefore reduced to its semiotic valence, it only helps to refer to other objects). This can be seen as a pejoration of the instrumental valence of the written symbol " -1 ": the oral speech bears all meaning; the mathematical notation is but a summary of this speech. In fact, the notation " -1 " bears the meaning of the calculation program - which is its instrumental valence: adding $n$ and then subtracting $n+1$ is equivalent to adding -1 ; its practicality as a tool is stronger than its mere semiotic valence. Besides, it is interesting to read the opposition between "in French" and "in maths", where "French" and "maths" are considered as competing languages. Logocentrism is met when a process - the choice of a functional notation - is replaced by an arbitrary convention, like the arbitrariness of linguistic signs.

In any case, $y$ seemed to neglect the possible justifications of the notation and, therefore, the meaning it can carry. As a consequence, he was not able to bring to life in his class a media-milieu dialectic that could lead students to propose notations, and the notation is imposed to them as arbitrary (as it appears to him). The pejoration of oralisation as a technical element prevented 
students from analysing calculation programmes and their equivalence, thereby preventing them from the necessity to denote calculation programs by such notations as " -1 ". In an interview made in June 2015, when asked to comment on the implementation of the SRP, $y$ explained that "I really felt this accordion-like understanding of students; there were times when I found some steps very easy, too easy: for instance, in the beginning, when working on calculation programs. 'I have never seen such an easy chapter,' I heard that".

It is not clear how far the use of calculation programmes as a tool for the construction of the technological and theoretical elements (justification of the introduction of new numbers, of the choice of notation for negative numbers, of calculation rules on these numbers, etc.) was well understood: it seems to be considered as plain and obvious, isolated from its possible use in the SRP. The profession of teacher does not currently include in its praxeological equipment the appropriate praxeologies necessary for the implementation of adequate media-milieu dialectics. In particular, there is a lack of teaching strategies for helping students explore different types of tasks, construct techniques (use many specimens, let students compare their results and techniques, etc.), and propose technological-theoretical speeches (let student analyse different techniques, let them justify or invalidate techniques, etc.). As a consequence, the use of calculation programmes is perceived as a mere step in a process with loosely related phases.

These were the difficulties met in the cooperation process between researchers and a teacher in the implementation of a finalised SRP. We will now turn to another form of cooperation between a researcher and a team of university teachers to design an open SRP.

\section{INITIATING AND MANAGING A PRAXEOLOGICALLY OPEN SRP}

The first author of this chapter (hereinafter designated by the letter $y^{\prime}$ ), with the help of a didactician $\xi$, initiated the project to set up an inquiry workshop following the work developed at the Collège du Vieux-Port (Chevallard 2011, Marietti 2009), but at university level: la prépa des INP in Toulouse (France). In this institution, students of engineering sciences, aged 18, get a two-years intense training in science and humanities as a preparation for their access to engineering schools. Therein, pedagogy is mainly a "pedagogy of teachers", based on the will to "teach" rather than to help the students elaborate knowledge by themselves. $y$ ' supported this workshop project for two years. After changing of institution, he was required to help a team of three teachers in the process of involving themselves in its pursuance. Two phases, building one's own praxeologies (design and management techniques, etc.) for the inquiry workshop, then disseminating them to colleagues, gave the opportunity to identify a series of difficulties met in the implementation of such a workshop. We present some of these difficulties and the effect they had on the remodelling of the teachers' professional praxeologies and, in particular, the emergence of a technique for the formulation of generating questions as well as some elements of a technology (justifications and groundings) for this technique.

The practical organisation of the workshop was as follows: 96 students were divided into groups of 24 students; each group was further subdivided into teams of four to five students. There were four 24-student groups, and two questions were asked (so two groups shared each question). The students were asked to elaborate an answer to the question, and they had 15 one-and-a-half-hour 
sessions (one every other week) to do it. Also, no a priori constraint was formulated about the tools used in the course of the work: internet, interviews with engineers or scholars, experimentations, software, books, questions to other teachers in the institution, etc., "everything" was possible.

\subsection{FIRST ENCOUNTER WITH, AND IDENTIFICATION OF, A PROFESSIONAL TYPE OF TASKS}

At first, $y$ ' selected two questions. A high-school teacher proposed the first question after reading an article in a mathematics journal for teachers. The second one was elaborated by $y$ ' after an inquiry based on the reading of a biographical article on Leonhard Euler. In the opinion of $y$ ' at this time, both questions had the advantage to ensure the encounter with some specific mathematical praxeologies (linear spaces, matrices, eigenvalues, etc.). More generally, all the ideas put forward by $y^{\prime}$ were closely related to some mathematical praxeology. Few days before the beginning of the workshop, the two selected questions were:

$Q_{1}$ : "Some photo editing software can sharpen blurry photos. How do they do it?"

$Q_{2}$ : "There are numerous constraints on the building of a bridge. In particular, the bridge is required to support heavy loads. How is it possible to foresee the maximum weight a bridge can withstand?" (as it was formulated within the teacher's logbook, LB).

Nevertheless, after a working session with the didactician $\xi$, the second question was abandoned in favour of the following, suggested by $\xi$ :

$Q_{2}$ : "Some mobile phones do not enter into standby mode until the user stops looking at them. How is it possible?"

Obviously, $\xi$ had something in mind while modifying the question: $y$ ' understood it as a way of proposing a sharper question, which would facilitate the start of the workshop (which may be one of the functions of a "generating" question). Also, this new question was not designed in order to ensure the study of mathematical themes - and even less, chosen mathematical themes.

In the following, we shall mainly focus on the moment of the first encounter with the following type of tasks:

$T_{Q}$ : "Design a generating question for an inquiry workshop,"

that is, on episodes where $y^{\prime}$ is first confronted with $T_{Q}$ and faces its realisation as problematic, and on the exploratory moment, when $y^{\prime}$ explores the type of tasks $T_{Q}$ and seeks to elaborate a technique to fulfil it.

Surprisingly enough, the exploration of $T_{Q}$ was constantly renewed over three years, and not only during the periods devoted to the design of the generating questions. Though it is expected that $T_{Q}$ has paramount importance before the start of the workshop, not necessarily once the workshop is launched, nonetheless, it would be a serious mistake not to take into consideration the influence the question might have on the management of the workshop all the way.

When $y^{\prime}$ started working with students in the exploration of $Q_{2}$, they were interested or even seduced: the freedom given to them to investigate in any direction and by any means, in a large 
autonomy, was appealing. Nevertheless, a long series of incidents eventually reached its climax on the eve of New Year's break, when a team refused to work during all session, only to end with a provocative speech directed to $y^{\prime}$, which substantially was blaming $y^{\prime}$ for not giving help and refusing to give precisions regarding the sort of answers that were expected. Other students had already complained: "What is it about? Do we have to program a phone? Do we have to understand the engineers' programs?" (LB); "we will never know whether the answer is satisfactory" (LB).

We can model the previous incident as follows. The workshop required that $y$ ' tackle the following type of tasks:

\section{$T_{M W}$ : "Manage a group of students in the frame of an inquiry workshop"}

The kind of technique that $y^{\prime}$ elaborated required not to give a direct answer (yes or no) to the question "is our answer satisfactory?", rather ask questions about the elements of the submitted answer to allow students to identify weaknesses in their proposition (a way of initiating a mediamilieu dialectics, where $y^{\prime}$ becomes an important part of the milieu). This technique raises an important issue: would it not be better if the students themselves were set in position to ask these questions? This can be tracked in the logbook:

$y$ ' handled the situation in compliance with the classical paradigm of study: he adopts the position of the bearer of knowledge [that is, he uses a pedagogy of teacher...] and establishes himself as the only judge of the adequacy of the submitted answer. By doing so, he can only comfort the team in the idea that he has definite expectations or even an idea of the answer, that he refuses to clarify to them. Another way to handle this little crisis would be to shift to the students the responsibility of the construction of the answer to the very question of the adequacy of the answer [...] y' could have suggested to this team to put their ideas to the test by exposing them to other students from other teams (LB).

Thus, $y$ ' was left with an important difficulty in the management of the group: letting the team set their own 'stopping criterion' leaves the students with a large topos, that is more autonomy in the managing of the study since they decide by themselves whether the inquiry is over or not, but it gives no means to tackle the problem raised by teams that believe that they have a satisfactory answer (and that their criterion for satisfactoriness is satisfactory). Letting the students choose the stopping criterion can lead them to minimal criterions. All these questions are related to the difficulty to handle a satisfactory media-milieu dialectics (we see how $y^{\prime}$ planned to include the other students into the milieu, etc.). This difficulty can be considered a problem not only of $y^{\prime}$, but of the whole profession (Cirade 2006, Chevallard \& Cirade 2010, Cirade 2012) as it is progressively confronted to issues relative to the new paradigm of questioning the world: implementing a genuine media-milieu dialectics does not belong to the professional types of tasks teachers are trained to. Here, it would have meant that the tentative answers elaborated by a team should have been considered as produced by a media (that is by an instance which is not neutral regarding it) and submit it to several milieus (that is instances which behave as "pieces of nature" regarding it: without positive or negative intentions); for instance, another team could be asked to 
use the chosen team's answer to make something (write an algorithm, etc.): if failing to do so, this team could criticise the proposed answer which would have to be further elaborated, etc.

In his later exploration of $T_{Q}, y^{\prime}$ took for granted that a good realisation of $T_{M W}$ relied on a satisfactory technique to perform $T_{Q}$. In other words, since the generating question itself can be considered as part of the milieu of its own study, the soundness of the media-milieu dialectics could depend on the inclusion of pieces of information in the generating question itself.

\subsection{HOW TO ASK A QUESTION, WHAT QUESTIONS TO ASK}

The exploration of TQ by y' raised the identification of at least two types of questions: technical and technological questions. The difference relies on the use of distinct interrogative pronouns - or on the possibility to reformulate questions using one of the two pronouns, how and why. A howquestion is a technical question in which it is expected that, by answering it, the person describes a technique commonly used in a given institution to accomplish the task referred to in the question. A why-question leads to an explanation (technology, in the sense of ATD) of the technique alluded to in the question. Questions Q1 and Q2 were first analysed by y' as being technological questions: though apparently how-questions, they pulled the students towards the necessity to explain why such or such technique was used, or why such or such device actually worked. To put it another way, y' thought at first that the issues met in the managing of the group was originated in the fact that the questions asked for explanations (technologies) and that the students were provided with no a priori criterion for the kind of admissible explanations. Indeed, many teams proposed popularised explanations_-leaving all technicalities unstated.

One could argue, though, that both questions are technical: $Q_{1}$ asks "how do they do it?", while $Q_{2}$ asks "how is it possible?". Answering the first question is to describe a technique used "to do it" in a given institution. To answer the second question, it is necessary to explain why a certain technique actually works ("how is it possible?" read as "why is it possible"); yet, to explain why something works, it is first necessary to show how it works. Therefore, the interpretation by $y$ ' of his difficulties was not entirely satisfactory. Nevertheless, it is a milestone in the process of exploration of $T_{Q}$ : the identification of the link between $T_{Q}$ and $T_{M W}$ indicates a certain direction for the elaboration of a technique for the realisation of $T_{Q}$, while the previous explanation (the questions were "technological") though incorrect, is a technological element of the praxeology under construction.

\subsection{DISSEMINATION OF A PROFESSIONAL PRAXEOLOGY}

After two years, $y^{\prime}$ left la prépa des INP and a new team of teachers took the responsibility of the inquiry workshop: an English teacher $\left(y_{1}^{\prime}\right)$, a mathematics teacher $\left(y_{2}^{\prime}\right)$ and a physics teacher $\left(y_{3}^{\prime}\right)$. None of them was acquainted with didactics of mathematics or with the pedagogy of inquirythough the three of them had already important thinking on their professional (pedagogical) techniques. The four teachers met a couple of times to discuss thoroughly the groundings of the workshop: $y^{\prime}$ warned $y_{i}^{\prime}$ about the difficulties specific to the management of such a workshop, he also emphasised on the possible relations between these difficulties and the generating question of the SRP. They all agreed to work collectively on the production of questions after $y^{\prime}$ gave some details on is own technique for $T_{Q}$. We will now shortly report on the process of formulating two 
questions for the workshop as it can be observed in the logbook of $y^{\prime}$ and in the e-mails exchanged with $y^{\prime}{ }_{i}$.

First, expectedly, $y_{2}{ }_{2}$ had designed questions related to mathematics (or that would rapidly reach mathematical problems). Consequently, $y^{\prime}$ swept aside these first questions by clarifying to $y_{2}{ }_{2}$ the aims of the workshop (we find here the first elements of the technique elaborated by $y^{\prime}$ in the first year of the workshop). After some days, two new questions arose:

How to detect counterfeit artworks?

How to make artworks impossible to counterfeit?

Comments by $y_{1}{ }_{1}$ : "Problem: can the question asked to the students result in a catalogue of existing techniques [...]? [...] Up to what point should we investigate to make sure that the question provides a field of inquiry neither too wide nor to closed [...], without investigating for them?" (Common logbook of $y_{1,2,3}, 9 / 13 / 2015$ )

The two questions are similar, and we see in the comments made by $y_{1}{ }_{1}$ that part of the technology for $T_{Q}$ has been acquired by $y^{\prime}{ }_{i}$ since they recognise the potential influence of the generating question on the ways the students might answer it. Here is a comment formulated by $y^{\prime}$ :

I think we should find a wording that would allow the students to enter into an inquiry that would not finish rapidly in a catalogue of existing answers.

Ideally, we should find wording such as: "These days, it is estimated that about 50\% of artworks on the market actually be counterfeit, despite the use of highly sophisticated scientific devices. Could you design and make a technical automated device that would ensure the authentication of an artwork?" The implication is to do "better" than existing solutions [...]. The writing "design and make" seeks to avoid the trap of an encyclopaedic catalogue of existing answers, and facilitates the answer to the question of the stopping criterion. [...] The question [...] should be converted to a question of the "could you do..."-type. (e-mail to $y_{i}$ 's, 9/11/2015).

We see that $y$ ' not only proposes changes in the formulation of questions but gives rationales for these modifications: his comments reach a technological level, and he elaborates further his own technique by putting forward the following key tool: "convert questions to 'could you do...' questions". This is an important modification of his own technique since questions $Q_{1}$ and $Q_{2}$ were not formulated this way. A few days later, the $y^{\prime}{ }_{i}$ wrote to $y^{\prime}$ about the questions they have produced:

Here they are:

Topic 1: To meet the energy needs of humanity, [how] can we use human beings themselves to produce daily useable energy?

Topic 2: $50 \%$ of works [currently circulating] in the art market might be counterfeit artworks: 
How to detect counterfeit artworks? Is it possible to make artworks impossible to counterfeit? Give us your opinion, thanks. (e-mail, $y_{1,2,3}^{\prime}$ to $y, 10 / 1 / 2015$; bracketed words are modifications brought by $y_{1}^{\prime}$ to a proposal of $y_{2}^{\prime}$ )

Though the two questions are already spaced apart from mathematics and also match somehow the additional demand that the questions should be sharp since both questions make clear reference to current sharp problems in our societies, they do not match comment of $y$ ' on the importance of formulating "could you do..." questions -even though we observe an attempt to "make technical" the questions by introducing interrogative pronoun "how". The exploration of $T_{Q}$ by the $y_{i}^{\prime}$ shows a limitation in the elaboration of the technique expected by $y^{\prime}$ :

As regards the two questions you have proposed, I feel they would benefit from the following rewritings:

1. To meet the energy needs of humanity, it can be contemplated to use the energy produced by human beings themselves. Could you suggest a device that would allow covering the needs in energy of the amphitheatre of la prépa using only (or mainly) the energy produced by its users?

2. Some sources claim that $50 \%$ of artworks circulating today on art market could be counterfeit: could you suggest a technique that would make impossible to counterfeit an artwork? (e-mail from $y$ to $y_{i}^{\prime}, 10 / 8 / 2015$ )

We see here that the new technique is used and we read "could you do..." questions. Nevertheless, the technology of this technique is not well shared with $y_{i}^{\prime}$ :

Thanks for the questions, I feel they are indeed more precise with your modifications. (email from $y_{1}{ }_{1}$ to $y^{\prime}, 10 / 8 / 2015$, our emphasis)

Obviously, though pedagogy of teachers focuses on questions, the evaluation of the quality of a question is generally grounded on clarity and precision requirements. In the pedagogy of inquiry, other questions can be asked about questions: about their capacity to generate inquiries, about the expectable range of these inquiries, etc. The logos of $y$ includes the idea that the generating question of an SRP can play an important part in the development of media-milieu dialectics: the fact of using "could you do..." questions is grounded on the hope that "doing" something will act as a milieu; whether the students can "do" something or not is like a "piece of nature" that will validate or not their answer according to their ability to use it to "do" something. This element can hardly be understood in the frame of pedagogy of teachers, where such a dialectics barely can exist. This operates as a constraint on the dissemination of praxeologies specific to the paradigm of questioning the world.

\subsection{EMERGENCE OF THE TECHNIQUE AND CONSTRUCTION OF THE LOGOS: MORE ABOUT GENERATING QUESTIONS}

The former episode shows an evolution in the technique elaborated by $y$ ': not only does he insist on "could you do" questions, he makes more explicit the nature of "you" in "could you do": "you" refers indeed not to an abstract person (as in philosophical dissertations) but to the subject of a given institution. In his seminar, Yves Chevallard (2010) emphasised on this: 
when [the institution] is elided [from the question] everything happens as if [the institution] were unique and as if there were a technique that is itself unique, and therefore implicitly universal, that answers the question. This is a language-effect that pushes back and hides the institutional relativity of praxeologies. (Our translation.)

Consequently, questions could be rewritten as to mention the institution (we take the example of $\left.Q_{1}\right)$ :

$Q_{1 \text { bis: }}$ What institutions dispose of a technique to sharpen blurry photos and what is this technique?

Following the technique proposed by $y^{\prime}$ to his colleagues, we could also propose a somewhat different question:

$Q_{1}^{\prime}$ : Some photo editing software can sharpen blurry photos. Could you do it yourself on your computer?

This writing would translate as follows:

$Q{ }_{1}$ : Some photo editing software can sharpen blurry photos. In the institution of the inquiry workshop at la prépa des INP, is it possible to elaborate a technique to do it?

Now we can imagine a more general technique for the design of generating questions for inquiry workshops:

$\tau_{Q}$ : Ask a question that is not related on purpose to some specific field of knowledge or discipline studied in the institution where the workshop is to take place. The question must be designed independently of the desire to lead students to meet a specific knowledge or theme. The question should be a sharp question. Finally, the question should be set at the level of an explicit institution (for instance the institution of the inquiry workshop itself).

The logos produced in the process of dissemination of $T_{Q}$ could be summed up as follows: the institution referred to in the question will be included in the milieu of the study. Consequently, the media-milieu dialectics will be easier to manage since the "stopping criterion" of the inquiry is grounded on the fact that any admissible answer will have to fit the needs of this institution (real or imaginary).

This logos explains somehow the path followed by $y^{\prime}$ in the study of $T_{Q}$ : his praxeological equipment is dominated (at least partially) by a pedagogy of teacher that makes difficult for him to handle media-milieu dialectics. The technique $\tau_{Q}$ softens the difficulty by anticipating it at the very level of the production of the generating question.

\section{CONCLUSION}

The prevailing pedagogy of teachers in the profession hampers the transition from a didactic paradigm focused on the visit of works to a paradigm of questioning the world. The training of teachers to implement didactic devices such as open or finalised SRPs raises such difficulties, even when didacticians lead the training. The lack of professional praxeologies for the generation and 
management of media-milieus dialectics appears as a pitfall for the dissemination of pedagogy of inquiry. In this chapter, this was seen at two levels: the performance of exploratory and technological-theoretical moments in a finalised SRP, as well as the production of a generating question, are problematic types of tasks for teachers, mainly because they are governed by a common logos, which puts forward the necessity for the teacher to lead the study. This is obvious in the situation explored in the second section of this work, but also in the one at the core of the third section since the missing logos of teachers about what the functions of questioning are, sufficiently explains their inability to endorse a new technique for the production of generating questions.

\section{REFERENCES}

Bernad, K. (2017). Une contribution à l'étude de conditions et contraintes déterminant les pratiques enseignantes dans le cadre de mises en œuvre de parcours d'étude et de recherche en mathématiques au collège (Doctoral dissertation). Université d'Aix-Marseille, France.

Bosch, M., \& Perrin-Glorian, M. J. (2013). Le langage dans les situations et les institutions. Essai de croisement de points de vue TAD et TS. In A. Bronner et al. (Eds.), Questions vives en didactique des mathématiques: problème de la profession d'enseignant, rôle du langage (pp. 267312). Grenoble, France: La pensée sauvage.

Chevallard, Y. (2002). Organiser l'étude. 1. Structures \& fonctions. In J.-L. Dorier et al. (Eds.), Actes de la lle École d'Été de didactique des mathématiques (p. 3-32). Grenoble, France: La pensée sauvage.

Chevallard, Y. (2003). Approche anthropologique du rapport au savoir et didactique des mathématiques. In S. Maury S., \& M. Caillot (Eds.), Rapport au savoir et didactiques (pp. 81-104). Paris: Éditions Fabert.

Chevallard, Y. (2007). Passé et présent de la théorie anthropologique du didactique. In L. Ruiz, A. Estepa, \& F.J. García (Eds.), Sociedad, escuela y matemáticas. Aportaciones de la Teoría Antropológica de lo Didáctico (705-746). Jaén, Spain: Universidad de Jaén.

Chevallard, Y. (2010). Journal $d u$ séminaire TAD/IDD. Retrieved from http://yves.chevallard.free.fr/spip/spip/IMG/pdf/journal-tad-idd-2009-2010-6.pdf

Chevallard, Y. (2011). La notion d'ingénierie didactique, un concept à refonder. Questionnement et éléments de réponse à partir de la TAD. In C. Margolinas et al. (Coord.), En amont et en aval des ingénieries didactiques. XVe école d'été de didactique des mathématiques. (pp. 81-108). Grenoble, France: La pensée sauvage.

Chevallard, Y., \& Cirade, G. (2010). Les ressources manquantes comme problème professionnel. In G. Gueudet, \& L. Trouche (Dir.), Ressources vives. Le travail documentaire des professeurs en mathématiques (pp. 41-55). Rennes, France: Presses universitaires de Rennes. 
Cirade, G. (2006). Devenir professeur de mathématiques: entre problèmes de la profession et formation en IUFM. Les mathématiques comme problème professionnel (Doctoral dissertation). Université de Provence-Aix-Marseille I, France.

Cirade, G. (2012) La formation des professeurs: entre analyse de praxéologies professionnelles et étude de problèmes de la profession. In J.L. Dorier, \& S. Coutat (Eds.), Enseignement des mathématiques et contrat social: enjeux et défis pour le 2le siècle - Actes du colloque EMF2012 (GT2, pp. 314-323). Geneva, Switzerland: Université de Genève.

Gascón, J. (2014). Los modelos epistemológicos de referencia como instrumentos de emancipación de la didáctica y la historia de las matemáticas. Educación Matemática, 25(E), 99-123.

Marietti, J. (2009). Le concept de PER et sa réception actuelle en mathématiques et ailleurs. Une étude préparatoire. (Mémoire de $1^{\text {ère }}$ année de Master Sciences de l'Éducation). Université AixMarseille I, France.

Matheron, Y., \& Noirfalise, R. (2011). Du développement vers la recherche: quelques résultats, issus du projet (CD)AMPERES, relatifs à la mise en oeuvre de PER dans le système d'enseignement secondaire. In M. Bosch et al. (Eds.), Un panorama de la TAD (pp. 57-76). Barcelona, Spain: Centre de Recerca Matemàtica.

Matheron, Y., \& Quilio, S. (2015). L'accès au milieu scolaire pour l'élaboration et l'expérimentation d'ingénieries didactiques de recherche: conditions et contraintes. In A-C. Mathé, \& E. Mounier, (Eds), Actes du séminaire national de didactique des mathématiques 2014 (pp. 80-91). Bordeaux, France: ARDM \& IREM Paris VII. 